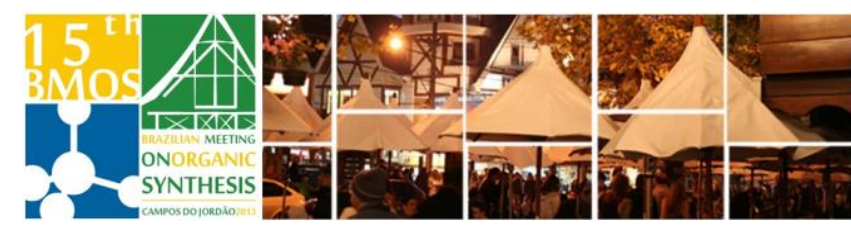

\title{
Studies in Organocatalyzed Direct Aldol Reactions under Solvent-Free Conditions
}

\author{
Rúbia Yano da Silva, Andréa Maria Aguilar* \\ Universidade Federal de São Paulo - Instituto de Ciências Ambientais, Químicas e Farmacêuticas \\ Rua Prof. Artur Riedel, 275, Diadema, SP, Brazil, CEP 09972-270 \\ *andrea.aguilar@unifesp.br, rubia.yano@unifesp.br
}

Keywords: direct aldol reaction, organocatalysis, green chemistry

\section{INTRODUCTION}

The aldol reaction is one of the most powerful synthetic tools for carbon-carbon bond formation, with a large application in stereoselective synthesis. In this area, organocatalysis is a strategy that recently has attracted a great deal of attention and become an intensively active research topic. ${ }^{1}$

After the pioneering work reported by List et al. $^{2}$ published in 2000 new organocatalysts proline derivatives have been designed for asymmetric direct aldol reactions. More recently, efforts have also been dedicated to asymmetric organocatalytic reactions using water as solvent to develop greener reaction media. $^{3}$

Following our studies involving application of organocatalyst 6 under mild condition reactions, herein we reported the results obtained in the aldol reaction promoted under solvent-free conditions.

\section{RESULTS AND DISCUSSION}

The organocatalyst 6 was prepared in 5 steps starting from available trans-4-Hydroxy-Lproline 1 and obtained in $51 \%$ overall yield as outlined in Scheme 1.

\section{Scheme 1}

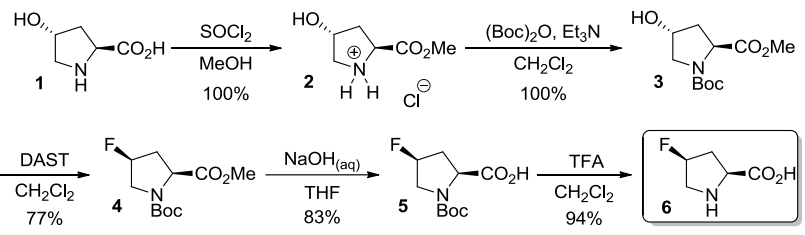

Subsequently, the efficiency of 6 was examined in the direct aldol reaction between cyclohexanone and $p$-nitrobenzaldehyde, ${ }^{4}$ under water versus solvent-free conditions (Entries 1-4, Table 1). Results previously described by our research group using 6 as organocatalyst afforded the aldol product $\mathbf{9}$ in good yields and stereoselectivity. ${ }^{5}$ Based on these results, the time to reaction completion was evaluated and it clearly appeared that the reaction conducted under neat conditions enhanced the reaction rate (Entries 2-4, Table 1). The scope and efficiency of this neat aldol reaction was examined with a series of arylaldehydes acceptors and cyclohexanone and the results are summarized in Table 1.

Table 1. Results obtained in the aldol reaction promoted by organocatalyst 6 and arylaldehydes. ${ }^{[\mathrm{a}]}$

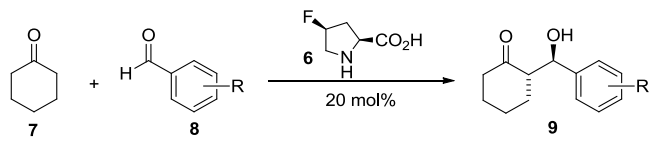

\begin{tabular}{|c|c|c|c|c|c|}
\hline Ent. & $\mathbf{R}$ & $\mathbf{T} .(\mathbf{d})$ & Yield(\%) & anti/syn $^{[\mathbf{b}]}$ & $\boldsymbol{e e}(\%)^{[\mathbf{c ]}}$ \\
\hline $\mathbf{1}^{[\mathbf{d ]}]}$ & $p-\mathrm{NO}_{2}$ & 7 & 75 & $65: 35$ & 99 \\
\hline $\mathbf{2}$ & $p-\mathrm{NO}_{2}$ & 7 & 92 & $87: 13$ & 99 \\
\hline $\mathbf{3}$ & $p-\mathrm{NO}_{2}$ & 4 & 91 & $79: 21$ & 98 \\
\hline $\mathbf{4}$ & $p-\mathrm{NO}_{2}$ & 1 & 92 & $85: 15$ & 97 \\
\hline $\mathbf{5}$ & $p-\mathrm{Br}$ & 1 & 80 & $94: 6$ & 72 \\
\hline $\mathbf{6}$ & $p-\mathrm{Cl}$ & 1 & 77 & $94: 6$ & 65 \\
\hline $\mathbf{7}$ & $m-\mathrm{NO}_{2}$ & 1 & 98 & $91: 9$ & {$[\mathrm{e}]$} \\
\hline $\mathbf{8}$ & $o-\mathrm{NO}_{2}$ & 1 & 98 & $91: 9$ & {$[\mathrm{e}]$} \\
\hline
\end{tabular}

${ }^{\text {[a] }}$ The reaction was carried out with aldehyde $(1 \mathrm{mmol})$, cyclohexanone (30 $\mathrm{mmol}$ ) at room temperature, ${ }^{[\mathrm{b}]}$ Determined by ${ }^{1} \mathrm{H}$ NMR, ${ }^{[\mathrm{c}]}$ Determined by HPLC analysis using a chiral column for the anti-isomer, ${ }^{[d]}$ Carried out in water (300 mol\%), ${ }^{[\mathrm{e}]}$ Analysis in progress.

The reaction has broad applicability with respect to the aldehydes employed. Electron deficient arylaldehydes (nitro, bromo and chloro substituted) in most cases afforded the corresponding aldol product 9 in excellent yields and stereoselectivity (Entries 4-8).

Other experiments are underway in our laboratory with neutral, electron-rich aldehydes and cyclopentanone, in order to evaluate the factors that influence the stereoselectivity of this reaction.

\section{CONCLUSION}

Application of easily synthesized organocatalyst 6 in aldol reaction afforded the aldol product 9 in good yield and stereoselectivity levels under mild conditions and in high concentrations, avoiding the use of solvents and minimizing waste.

\section{ACKNOWLEDGEMENTS}

We are grateful to CNPq, Fapesp and Capes.

\section{REFERENCES}

a) Heravi, M. M. et al., Tetrahedron Asymmetry 2012, 23, 1431. b) Bisai, V. et al., Tetrahedron 2012, 68, 4541.

${ }^{2}$ List, B., Lerner, R. A., Barbas, C. F., III J. Am. Chem. Soc. 2000, 122, 2395.

${ }^{3}$ Hernández, J. et al., Chem. Commun. 2012, 48, 5396.

${ }^{4}$ Mase, N. et al., J. Am. Chem. Soc. 2006, 128, 734

${ }^{5}$ Silva, R. Y.; Soares, B. M.; Aguilar, A. M. 36 ${ }^{\mathrm{a}} \mathrm{RASBQ}$, Águas de Lindóia São Paulo, 2013.

$15^{\text {th }}$ Brazilian Meeting on Organic Synthesis - 15 $5^{\text {th }}$ BMOS - November 10-13, 2013 - Campos do Jordão, Brazil 